Int. J. Electrochem. Sci., 15 (2020) $505-514$

International Journal of

ELECTROCHEMICAL

SCIENCE

$\underline{\text { WwW.electrochemsci.org }}$

\title{
Acetylcholinesterase based rGO-TEPA-Copper nanowires biosensor for detecting malathion
}

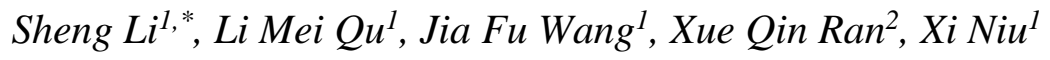 \\ ${ }^{1}$ The Key Laboratory of Plant Resources Conservation and Germplasm Innovation in Mountainous \\ Region (Ministry of Education)/Guizhou Key Lab of Agro-Bioengineering, Institute of Agro- \\ Bioengineering and College of Life Sciences, Guizhou University, Guiyang 550025, Guizhou, China \\ ${ }^{2}$ Faculty of Animal Science and Veterinary Medicine, Guizhou University, Guiyang, China. \\ *E-mail: $\underline{\text { listen318@163.com }}$
}

doi: $10.20964 / 2020.01 .75$

Received: 8 September 2019 / Accepted: 3 November 2019 / Published: 30 November 2019

This study aimed to develop a biosensor for rapid detection of malathion. We established a biosensor by immobilizing acetylcholinesterase (AChE) to glassy carbon electrode (GCE) with the modification of reduced graphene oxide-tetraethylenepentamine (rGO-TEPA) and the copper nanowires (Cu NWs). The rGO-TEPA-Cu NWs was used to improve the electrode conductivity and enhance the electrode loading ability for AChE. Chitosan (CS) was used to as the supporter for AChE. Exposure to malathion inhibited AChE activity and decreased the current significantly. We optimized the detection condition and found that AChE-CS/rGO-TEPA-Cu NWs/GCE showed a linear association with malathion from $1 \mathrm{ng} / \mathrm{mL}$ to $20 \mu \mathrm{g} / \mathrm{mL}\left(\mathrm{R}^{2}=0.989\right)$ and the detection limit was $0.39 \mathrm{ng} / \mathrm{mL}$. Furthermore, analysis of real samples using the biosensor showed satisfactory results. In conclusion, the biosensor we developed in this study has potential application to the detection of organophosphate insecticides such as malathion.

Keywords: malathion; organophosphate insecticides; biosensor; nanowire; acetylcholinesterase

\section{$\underline{\text { FULL TEXT }}$}

(C) 2020 The Authors. Published by ESG (www.electrochemsci.org). This article is an open access article distributed under the terms and conditions of the Creative Commons Attribution license (http://creativecommons.org/licenses/by/4.0/). 